\title{
Autobiographical memory: genesis, functioning, discursive implementation
}

\section{[Автобиографическая память: генезис, функционирование, дискурсивная манифестация]}

\author{
Anna A. Petrova - Larissa N. Rebrova
}

DOI: 10.18355/XL.2016.09.02.11-36

\begin{abstract}
Аннотация
Статья посвящена исследованию дискурсивной манифестации автобиографической памяти, позволяющей осмыслить социальную, коммуникативную природу данного феномена. Указанные характеристики позволяют говорить о познавательном потенциале лингвистики в рамках исследовательской парадигмы памяти. В статье исследуются генезис и развитие форм автобиографической памяти в раннем периоде онтогенеза, взаимосвязь данных процессов со становлением речи, Я-концепции, когнитивно-речевых, дискурсивных компетенций; изучаются закономерности дискурсивной актуализации сформированной автобиографической памяти, манифестации ее функционально-структурных характеристик. Показывается, что сформированная автобиографическая память как личностно-когнитивная система организует и упорядочивает фрагменты индивидуального прошлого, участвует в формировании самоидентичности, имеет уровневую структуру, которая сопрягается с разнотипными формами обработки автобиографического материала и организационными формами индивидуального опыта, выполняет разные функции, что в совокупности определяет закономерности соответствующих дискурсивных практик.

Ключевые слова: автобиографическая память, генезис автобиографической памяти, развитие форм памяти, дискурсивные практики, организационные формы автобиографического материала, уровневая структура автобиографической памяти, тематические доминанты, функции автобиографической памяти
\end{abstract}

\section{Введение}

Память представляет собой активно разрабатываемый объект междисциплинарных исследований, что обусловливается значимостью, сложностью и многомерностью данного феномена, функционирующего как на уровне общества, так и на уровне индивида. Социальная, коммуникативная, семиотическая природа памяти, ее преимущественно языковая манифестация позволяют говорить о познавательном потенциале лингвистики в данной сфере и закономерности интеграции существующих внутридисциплинарных лингвистических знаний в исследовательскую парадигму памяти (Shamne, Rebrina, 2013). Спектр дискурсивных практик памяти, в том числе и автобиографических самопрезентаций, постоянно растет.

Одной из подсистем памяти, выделяемой с биопсихологической и социологических точек зрения является автобиографическая память (термин введен в 1976 г. Вж. Робинсоном), выполняющая собственные функции и характеризующаяся определенными функциональными закономерностями. Анализ автобиографических практик (на материале немецкого языка) позволяет 
сделать значимые наблюдения о функционально-структурных характеристиках автобиографической памяти (АП).

При этом мы исходим из следующих теоретических положений. АП долгосрочная (по временному параметру), индивидуальная, декларативная (по типу социального субъекта и по типу содержания) и эксплицитная (осознанно воспроизводимое содержание) память; сопряжена с эпизодической памятью, содержание которой составляют личностно значимые события жизни субъекта как их участника или свидетеля. Автобиографическая память существует в психическом хронотопе (психическое пространство и время освоенных данной личностью смыслов); предполагает активную адаптацию к актуальным потребностям индивида, социальному контексту (Baddeley, 1992; Conway, 1993); играет значимую роль в структуре идентичности личности как результате социализации, индивидуализации и комбинации идентичности социальной (интериоризированные личностью социальные роли, переживание причастности к социальным группам) и самоидентичности. Самоидентичность складывается из персональной (переживание знаний об индивидуальных психологических, поведенческих, физических характеристиках) и автобиографической (переживание единства личной истории жизни, преемственности ее этапов) (Nurkova, 2004: 78). Все типы идентичности предполагают обращение к АП. АП существует в вербальной форме (нарративная организация); характеризуется атрибутированностью содержания как личного; особой временной организацией материала; эмоционально-мотивационной и социокультурной обусловленностью. Автобиографическое воспоминание регулируется взаимодополняющими принципами соответствия (отражает реальный опыт) и когерентности (соотносится с остальными воспоминаниями и видением индивида себя) (Blagutina, 2009). АП - личностно-когнитивная система, управляемая актуальными потребностями субъекта, опосредуемая социокультурными средствами (нарративные структуры, жизненные сценарии), обнаруживающая свою специфику в онтогенезе, возникая как интерпсихическая функция в форме разделения совместной актуализации и развиваясь в интрапсихическую функцию (Nurkova, 2008: 17-18, 2004: 3). Данной подсистеме свойственны собственные функции: прагматическая, саморегуляционная, коммуникативная, экзистенциальная (Vasilevskaya, 2008). Автобиографические практики представляют собой культурно-обусловленную, социализированную, опосредованную, материализованную форму фиксации АП, определяемую законами и нормами речи и механизмами памяти.

\section{Задачи и материал}

В соответствии с поставленной целью, проанализировать генезис, развитие форм автобиографической памяти, описать ее коммуникативную природу и дискурсивные аспекты ее функционирования, в рамках данного исследования решаются следующие исследовательские задачи:

I. изучение генезиса автобиографической памяти (АП); развития форм памяти в раннем периоде онтогенеза.

II. изучение закономерностей дискурсивной актуализации сформированной автобиографической памяти и организации субъективного отражения индивидом его жизненного пути; дискурсивной манифестации функционально-структурных характеристик АП.

Заявленные задачи исследования предусматривают следующие исследовательские шаги:

I. При изучении генезиса и развития форм автобиографической памяти в раннем периоде онтогенеза: 1) проведение пилотажно-ассоциативных 
экспериментов с целью выяснения уровня когнитивно-речевого развития детей; 2) изучение видео- и аудио записей и транскриптов бесед взрослых с ребенком; 3) осуществление детального описания дискурсивных практик в раннем онтогенезе с определением коммуникативного статуса реплик ребенка и взрослого, и выявления стратагемно-тактических приемов последнего, способствующих преодолению детской амнезии.

II. При изучении дискурсивной актуализации сформированной АП взрослого человека и манифестации в соответствующих дискурсивных практиках функционально-структурных характеристик АП: изучение 1) дискурсивной манифестации форм организации автобиографического материала в памяти; 2) объективации уровневой структуры АП в автобиографических практиках; 3) тематических доминант дискурсивной реактуализации индивидуального прошлого; 4) дискурсивной манифестации функций АП.

I. Материалом лингвистического исследования памяти в периоде раннего онтогенеза послужили аудио- и видеозаписи коммуникации немецкоязычных дошкольников в возрасте от 1 года 6 месяцев до 7 лет; использовались данные корпусов, в том числе мультимедийных: немецкой детской речи Института немецкого языка г. Мангейма (Германия), CHILDES Transcript Browser (CHILDES) с транскриптами речи немецкоязычных детей возрастного интервала от 3 до 7 лет, а также собственные аудио- и видео записи.

II. Исследуемый материал представляет собой инициируемые высказывания субъекта, предполагающие выстраивание индивидуального опыта в хронологической и тематической последовательности, выявление регулярных характеристик и мотивов личности. В качестве источников использовались данные Немецкого языкового архива Института немецкого языка в г. Мангейме (DSAv). Материал в корпусах представлен в максимально «естественном» виде, что означает минимальное влияние «со стороны», включение не только лингвистической, вербальной и невербальной (интонация, смысловые ударения и пр.), но и экстралингвистической (паузы, вздохи, смех, покашливания и др.) информации, что способствует пониманию неполных фраз, экспликации имплицитных смыслов и модуса высказываний. При этом мы учитываем, что прошлый автобиографический опыт реактуализируется в соответствии с его релевантностью для рассказчика, форма повествования соотносится со структурой жизненного опыта, а сам вспоминающий субъект при неподготовленном высказывании в меньшей степени склонен к самопрезентации; что данные образцы коммуникативных практик характеризуются стремлением респондента к целостности и законченности повествования об эпизодах своей жизни; сгущением, то есть селективностью воспроизведения прошлого опыта, ориентацией на субъективно значимые события; детализацией (склонностью говорящего к объяснению и уточнению взаимосвязей); аутентичностью воспроизведения автобиографического опыта (конгруентность личности, ее качествам, индивидуальной истории жизни) (Schütze, 1984: 79).

\section{Результаты}

I.

При изучении генезиса различных подсистем долговременной памяти мы опирались на концепции К. Нельсон, В.В. Нурковой, А.Н. Леонтьева, В. Ротенберга. Модель долговременной памяти включает в себя три подсистемы: эпизодическую, общую и автобиографическую. По мнению К. Нельсон, первой в онтогенезе складывается эпизодическая память, имеющая буферную природу

XLinguae Journal, Volume 9 Issue 2, April 2016, ISSN 1337-8384 
и фиксирующая специфические эпизоды. По мере того, как у ребенка развивается вербальное мышление, эпизоды обобщаются и их специфичность утрачивается. К моменту формирования автобиографической памяти (возраст самого раннего автобиографического воспоминания 3 - 4 года), ребенок уже располагает запасом специфических эпизодов прошлого (эпизодическая память) и представлением о типичных событиях жизни человека (общая память).

Автобиографическая память как психологическая структура, ответственная за формирование, поддержание и развитие самосознания личности в диахроническом измерении, определяется как высшая мнемическая функция, организованная по смысловому принципу, оперирующая с личностно отнесенным опытом (Nourkova, 1996; Nurkova, 2009). Одним из наиболее продуктивных и эвристичных подходов к изучению автобиографической памяти является социокультурный подход, согласно которому автобиографическая память является онтогенетическим новообразованием, имеющим культурно специфичные формы и развивающимся в социальном взаимодействии. Автобиографическая память рассматривается как продукт развития эпизодической памяти, где значимой является спецификация времени и места происшедшего.

Анализ становления начального уровня функционирования ранних непроизвольных форм памяти ребенка в условиях развития дискурсивных практик со взрослыми по данным нашего исследования подтвердил и показал, что:

\section{1. Развитие форм памяти связано со становлением межполушарных структур мозга.}

Исследуя функции и онтогенез межполушарной асимметрии и основываясь на теоретико-экспериментальных данных о межполушарной функциональной дихотомии, В. Ротенберг (Rotenberg, Weinberg, 1999; Downar et al., 2002; Devinsky, 2000; Chernigovskaya, Deglin, 1986), устанавливают, что правое и левое полушария уже на ранних этапах онтогенеза имеют определенные качества.

Открытия в области онтогенеза межполушарной асимметрии (Schore, 2003; Saugstad, 1998) подтверждают, что первые 2-3 года у ребенка доминирует правое полушарие, обеспечивающее первоочередное целостное "схватывание" объектов и явлений внешнего мира. Правое полушарие обеспечивает эмоциональный контакт с матерью; способность к речевому общению также закладывается на этом этапе доминирования правого полушария, - в конце второго года жизни дошкольника. Первоначальной деятельностью правого полушария объясняется и раннее становление просодической системы речевых реакций дошкольника. Моторика речи появляется позднее, когда ребенок начинает артикулировать звуки (Petrova, 1997: 97).

Логическая же память является функцией левого полушария. Она может быть схематично представлена в виде множества изолированных линейных цепей, каждое звено которых соединено не более чем с двумя другими - предшествующим и последующим.

С передними, фронто-орбитальными отделами правого полушария, связаны сложные и только человеку принадлежащие функции, такие как формирование Я-образа, от которого зависит выбор поведенческих альтернатив в конфликтных ситуациях (Rotenberg, 1982; Craik et al., 1999; Keenan et al, 2000, 2001; Decety, Sommerviile, 2003; Newen, Vogeley, 2003); чувство эмпатии (Shamay-Tsoory et al., 2003); чувство юмора (Shammi, Stuss, 1999); то, что получило название theory of mind - способность понять, как тебя понимают другие (Newen, Vogeley, 2003; Platek et al., 2004); автобиографическая 
эпизодическая память, тесно связанная с самовосприятием (Markowitsch, 1995; Lou et al., 2004) и базирующаяся на зрительной образной памяти (Rubin et al., 2003); способность отличить себя от других (Decety, Chaminade, 2003), наконец, способность к творческому решению задач (Springer, Deutsch, 1981; Bowden, Beeman, 1998). По своей значимости для интеграции человека в мире эти функции едва ли не превосходят значимость тех функций симметричных отделов левого полушария, которые рассматривались как высшие психические (Rotenberg, 2009).

2. Развитие автобиографической формы памяти тесно связано со становлением речи в онтогенезе, в особенности с формирования компетенции устного рассказа.

Усвоение языка как одного из видов коммуникативных систем человеческим индивидуумом является сложным процессом, охватывающим весь спектр языковых уровней, включающим фонологию, грамматику, лексику. Наряду с фонетико-фонологическими, морфолого-синтаксическими и семантическими компетенциями существует и процесс усвоения прагматических и дискурсивных компетенций, которые, вместе взятые, формируют обширный концепт базисных показателей, включающий в себя также и область усвоения письма (Petrova, 2010: 325).

Мы различаем следующие квалификаторы: фонетико-фонологические, прагматические (первый уровень), семантические, морфолого-синтаксические, дискурсивные, прагматические (второй уровень), орфографические (первый уровень), орфографические (второй уровень) (Referenzrahmen zur..., 2008a: 1821).

Прагматические базисные показатели первого уровня образуют коммуникативную основу для усвоения языковых компетенций в интервале до двухлетнего возраста. Первоначально они усваиваются в период ранней интеракции ребенка и, прежде всего, в паре со своими первыми партнерами по коммуникации - родителями или сверстниками. Дошкольник с помощью языка обучается распознавать цели общения партнера с одной стороны, с другой же, самостоятельно применять язык в его первоначальной форме для достижения собственных коммуникативных намерений. При этом ребенок усваивает элементарные языковые и коммуникативные образцы и схемы таким образом, чтобы быть в состоянии отличить собственные цели и перспективы общения от подобных партнера по коммуникации и, исходя из этого, строить собственное языковое поведение. Такая тактика вербального и невербального поведения будет иметь решающую роль в ориентации при прослушивании (аудировании) текстов.

Если речь идет о дискурсивных показателях, то подразумеваются основные структуры формальной речевой коммуникации, т.е. овладение опытом мены коммуникативных ходов и тактик. Одной же из центральных областей действий таких показателей является обладание способностями монологического сообщения, складывающегося с возраста трех лет сначала как устное, а затем в более позднем возрастном интервале и как письменное коммуникативные действия.

Становление компетенции овладения устным рассказом характеризуется определенными онтогенетическими этапами и связано не только с усвоением дискурсивных умений дошкольника, но и находится в тесной связи с совершенствованием мыслительных операций ребенка, постепенно облекающихся в языковую форму. Следующие возрастные уровни важны для генеза любого рассказа, включая рассказ по картинке, пересказ устное воспроизведение услышанного, увиденного, автобиографический XLinguae Journal, Volume 9 Issue 2, April 2016, ISSN 1337-8384 
рассказ (далее АР): 1) возраст 3-4 лет, который характеризуется рассказомизложением в широком смысле, без точной характеристики типа повествования, иными словами, не ясно, идет ли речь о самом повествовании, описании или воспроизведении. Первые рассказы обрывисты, непоследовательны, не обладают четкой структурой изложения и возможны только при поддержке взрослого партнера по коммуникации; хронотоп событий не эксплицируется лексически (отсутствуют лексические маркеры хроно-пространственной последовательности событий, такие как «сначала, потом»), но передаются имплицитно, путем выстраивания определенной событийной последовательности с употреблением усвоенных в этом возрастном интервале временных презентно-перфектных глагольных форм; 2) в возрасте 5-6 лет наблюдается существенной изменение в усвоении компетенции рассказа; так, наряду с рассказом-изложением в широком смысле, начинает развиваться рассказ - изложение в узком смысле, в котором пережитое или представленное событие находит свое четкое языковое воплощение, что выражается прежде всего в усложненном структурировании и компклесности в представлении события; наблюдается собственная оценка увиденного/услышанного, что связывается с развитием саморефлексии и «Я-концепции». Так, в речи детей присутствуют высказывания с эмоциональной оценкой: «и я испугался/und ich hab Angst gehabt», «это было неопасно/das war nicht gefährlich» и т.д.; 3) в возрасте 7-8 лет фиксируется рассказ-переживание-воспоминание с увеличением флексибельности в употреблении языковых средств; 4) возрастной интервал от 9 лет и далее характеризуется увеличением разнообразия эмоциональных квалификаций рассказа, расширением субъектно-предикатной сетки предложений с включением актантных маркеров и коннекторов для выражения причинно-следственных и временных отношений, а также развитием и совершенствованием нарративных компетенций.

\section{3. Развитие автобиографической памяти связано со становлением многозначного Я-образа и Я-концепции.}

На ранних этапах онтогенеза необходимо интегральное восприятие мира и самого себя как неотделимого (без рефлексии) его компонента для адаптивной интегральной реакции на любое внешнее воздействие. Благодаря взаимодействию со сложными явлениями, включая эмоциональные контакты, в раннем возрасте складываются предпосылки к последующему развитию многозначного мышления, основания для реализации которого создаются позднее. На втором этапе развития формируется мышление, обеспечивающее анализ, дифференциацию явлений и создание однозначных моделей, удобных в коммуникации. Одновременно происходит выделение себя из мира, рефлексия. Именно выделение себя из мира является обязательным предварительным условием формирования Я-образа как высшей психической инстанции (Vigotski, 1999). Предметно-практическая сторона деятельности, в процессе которой происходит социализация ребенка - освоение социального опыта через освоение орудий, знаков, символов, овладение социально зафиксированными действиями, их социальной сущностью, выработка способов обращения с предметами, при оценке своих действий, умения присматриваться к себе, примерять себя к окружающему, рефлексии на свои действия и поведение, связана с утверждением позиции «я среди других»- «я в обществе». Иными словами, развертывание определенной позиции ребенка по отношению к людям и вещам приводит его к возможности и необходимости реализации накопленного социального опыта в такой деятельности, которая наиболее адекватно отвечает общему уровню психического и личностного развития; и 
автобиографическое воспоминание -автобиографический рассказ как форма проявления АП занимает здесь центральное место.

4. Формирование автобиографической памяти связано с развитием когнитивно-речевых способностей ребенка.

Многочисленные наблюдения и материал специальной литературы (Lurija, 1998: 92; Gorelov, 2003: 30-31) свидетельствуют о том, что развитие ребенка характеризуется несинхронностью речевого и умственного процессов. Эксперимент по восприятию связного текста в группах разноязычных детей средней и старшей ступеней онтогенеза с привлечением ассоциативной методики выявил некоторые «ножницы» между умением слушать, воспроизводить, понимать и беседовать самостоятельно (возраст 5.0). Установлено, что значительная часть лексических единиц усваивается в одном двух значениях и ограничена именно теми словоупотреблениями, которые фиксировались в речи взрослых носителей языка, т.е. поверхностная структура усваивалась дошкольниками вполне. Иными словами, понимание всех текстовых единиц не обязательно ведет к пониманию связного текста. Необходимо еще и знание смысла (ситуации, события), которое приходит лишь с постижением жизненного опыта. То же касается и умения ребенка, включая старшие этапы онтогенеза и даже подростковый возраст, облечь воспоминания в языковую форму, будь то устная или письменная фиксация. Совершенно ясно, что данный вид памяти, реализуясь в форме воспоминаний, должен пройти определенный путь как когнитивного, так и речевого развития дошкольника.

\section{5. Автобиографическая память развивается в процессе коммуникации и диалогового взаимодействия с взрослыми партнерами по общению, способствующими усвоению дискурсивных компетенций ребенка.}

Исследуя генез автобиографического рассказа Л. В. Никанорова и В. В. Нуркова фактически подтверждают гипотезу K. Nelson о преодолении детской амнезии и начальных этапах ранних воспоминаний, датируя средний возраст первого воспоминания 3,5 годами и понимая под таким преодолением детской амнезии “модель социальной интеракции”, иначе диалог матери и ребенка. На ранних ступенях развития детской коммуникации (по нашему материалу до 3-х летнего возраста ребенка) модель социальной интеракции не включает адекватной реакции дошкольника на речевые стимулы взрослого: просьба рассказать об увиденном событии остается без ответной реакции, что побуждает взрослого интуитивно и эмоциональных фокусировать внимание ребенка на наиболее важных деталях прошлого, формируя определенные образывоспоминания и отражая таким образом комплексную структуру автобиографического рассказа.

АП представляет собой самостоятельный вид памяти, единицами организации которой являются автобиографические воспоминания.

Наши данные подтверждают также, что:

1.Взрослый, обладающий сложившейся АП, транслирует ее ребенку.

2. В ходе взаимодействия ребёнка со взрослым над чувственным базисом восприятия надстраиваются значение и личностный смысл; в этой триаде АП становится автобиографическим фактом (Никанорова, 1998).

Согласно Nelson, структура АР состоит из описания отдельных эпизодов из недавнего прошлого опыта ребенка, к рассказу-воспоминанию о которых дети избирательно «принуждаются» взрослыми коммуникантами, владеющими временными стратегиями датировки событий и прививающими навыки их использования в прагматических типах диалогов. При этом подчеркивается, что прагматический тип оказывает тормозящее развитие на АП,

XLinguae Journal, Volume 9 Issue 2, April 2016, ISSN 1337-8384 
в отличие от рассказывающего типа диалоговой дискуссии, способствующей развитию АП. Важным на наш взгляд здесь является идея о стратагемнотактических способах реализации и развития АП ребенка, предпринимаемого взрослым, что находит яркое воплощение при трансляции воспоминаний уже взрослого индивидуума (чему посвящено наше дальнейшее исследование).

Дискуссионными с нашей точки зрения являются следующие моменты: так, согласно А.P. Алюшевой (Aljuscheva, 2012, www), исследующей функциональный репертуар автобиографической памяти и ее первичные функции - коммуникативные, что не вызывает сомнения, - ребенок вспоминает для того, чтобы поддерживать общение со взрослым; согласно В.В. Нурковой же, ребенок в двухлетнем возрасте рассказывает взрослому о каждодневных рутинных событиях (Nurkova, 2012, www), - на ранних этапах онтогенеза это не возможно, поскольку ребенок не обладает развитой речевой системой средств для целостных воспоминаний и общение поддерживается не только и не столько за счет них. В раннем онтогенетическом периоде развития также не представляется возможным и решение задач обобщения многообразия жизненных историй, поскольку ребенок не обладает стабильными хронопространственными представлениями и умениями причинно-следственными обобщений, к которым относится усвоение презентно-перфектных форм и личных местоимений (например, оппозиция «я-мы»), которые не успевают сформироваться к возрасту двух лет. Схемы же событийной организации жизни - сценарии, которые как «идеальные формы» (по Л.С. Выготскому) интериоризуются и используются ребенком для структурирования автобиографической памяти, возможны лишь на этапе подросткового развития после 6 лет.

На начальных стадиях развития автобиографической памяти дети заимствуют модель обращения к автобиографическому опыту, которую им презентируют родители. Это подтверждается нашим материалом с тем уточнением, что родители пытаются концептуализировать воспоминания детей, вычленяя наиболее яркие, по их мнению, события недавнего прошлого, задействуя стратегию «Расскажи мне, что ты видел вчера, где ты был вчера», и это, скорее, дидактический тип взаимодействия с взрослым (о дидактическом типе см. Aljuscheva, Nurkova, Fivush, Bauer, Nelson), однако, по нашему материалу не наблюдалось неустанного повторения родителем ребенку истории о произошедшем событии, скорее, что на ранних стадиях онтогенеза в спонтанных бытовых диалогах во время повседневного общения при выполнении определенных бытовых видов деятельности для родителя, как и для ребенка, важнее совместное участие в процесс общения и сопровождение таких видов деятельности вербальным описанием, нежели «вдалбливание» ребенку определенных воспоминаний. Напомним, что к таким видам деятельности, способствующим развитию психики человека в онтогенезе, относятся: 1) непосредственное общение младенца со взрослыми; 2) предметноманипулятивная деятельность, характерная для раннего детства; в процессе ее выполнения ребенок усваивает исторически сложившиеся способы действий с определенными предметами; 3) сюжетно-ролевая игра, характерная для дошкольного возраста.

Предположение о том, что ранним источником индивидуализации субъективной картины личного прошлого является особый «провокационный» стиль родительского общения по поводу автобиографических воспоминаний ребенка (Aljuscheva, 2012, www), когда родители провоцировали детей на неправильное воспроизведение истории, подвергали сомнению воспоминания детей, намеренно включали в рассказ ложную информацию, также 
представляется спорным, поскольку на ранних этапах онтогенетического развития, в том числе в периоде первых фрагментарных воспоминаний ребенка, такой тип диалогового взаимодействия неизбежно приведет к прерыванию коммуникации или превращению ее в вариант квазиинтеракции с нарушенными прагматическими установками и ложной мотивацией, что никак не является целью взрослого партнера, даже если его намерения связаны с побуждением к озвучиванию верного воспоминания ребенка или к стимулированию к участию в совместной диалоговой деятельности. Данное может быть фактом лишь на более поздних этапах онтогенеза (Petrova, 2003: 17-30).

Итак, по данным нашего исследования, в спонтанных бытовых диалогах взрослого и ребенка во время выполнения рутинных каждодневных домашних операций как-то совместная игровая деятельность, рассматривание и чтение книг, изготовление игрушек и других поделок, - при генерировании совместных с взрослым или самостоятельных рассказов об автобиографическом эпизоде, основными типами диалогового взаимодействия в паре «ребеноквзрослый» был разрабатывающий дидактический тип, который управляется системой вопросов и подсказок взрослого и придает автобиографическому воспоминанию смысл самостоятельного действия (Nurkova, 2012, www).

Материалом нашего исследования - изучение формирования и становления устного рассказа как первоначальной формы трансляции АП и, таким образом, преодоления детской амнезии, - послужили аудио записи спонтанных диалогов немецкоязычных взрослого и ребенка и их транскриптов из мультимедийного корпуса CHILDES Transcript Browser (CHILDES). Возраст детей - от 3 до 7 лет.

Эпизод 1. (CHILDES, Sebastian/sb000017 - здесь и далее)

Описание транскрипта: транскрипт (здесь и далее) начинается перечислением участников диалога с указанием возраста, времени проведения записи и ее длительности, места и ситуации - кратким общим содержанием беседы, которую мы приводим без изменения по материалам транскрипта.

Возраст ребенка - 3 года 2 месяца 12 дней; в транскрипте (здесь и далее) как CHI 3;02.12; MUT- мать; RIG - родственница семьи.

0 @Loc: Germanic/German/Rigol/Sebastian/sb030212.cha

1 @PID: 11312/c-00023765-1

$2 @$ Begin

$3 @$ Languages: deu

4 @Participants: CHI Sebastian Target_Child, MUT Mutter Mother ,

RIG Frau_Rigol Observer

$5 @$ @ID:

deu|Rigol $|\mathbf{C H I}| \mathbf{3 ; 0 2 . 1 2} \mid$ male|group $|\mathrm{MC}|$ Target_Child $\mid$ Gesamtschule ||

6@ID:

deu|Rigol|MUT|34;00.00|female|group $\mid$ MC $\mid$ Mother|Realschule_Lehre ||

7 @ID: deu|Rigol|RIG|65;00.00|female|group $\mid$ MC $\mid$ Observer|Studium||

$8 @$ Media: 74sb03-1, audio, missing

9 @Comment: Filename: sb030212.cha

$10 @$ @ate: 06-APR-1995

$11 @$ Comment: Dependent: exp,spr

$12 @$ @ape Location: LP , 158, 3:25:00-3:56:00, VHS SEBASTIAN VIII (3)

$13 @$ Comment: SEBASTIAN-Datei: 74; Gesamtkorpus: 1219; Datum:

06.04 .95

14 @Comment: Transcriber: auth. by Rigol

$15 @$ @ime Duration: 10:00-10:30

16@Location: Wohnzimmer der Eltern

XLinguae Journal, Volume 9 Issue 2, April 2016, ISSN 1337-8384 
$17 @$ Situation: Zunächst spielt Sebastian herum; er holt sich seine Eisenbahn von der Großmutter und stellt sie mir vor. Danach erzählt er mir, wie er mit dem Vater zum Erdesieben auf den Acker gefahren ist und was er mit ihm des weiteren vorhat. Christian ist inzwischen wach geworden und wird in das Zimmer geholt. Sebastian macht viel Quatsch, neckt seine Mutter, die immer wieder versucht, ihn zur Ernsthaftigkeit zu veranlassen. Beide unterhalten sich über ein Vorhaben am Samstag; die Eltern wollen ausgehen. Sebastian neckt die Mutter mit Bier und Schnaps. Als sie ihm aber dann vorstellt, was sie alles nicht mehr kann, wenn sie betrunken ist, beginnt Sebastian zu weinen. Später benutzt er die Mutter als Reittier. Am Ende schlägt ihm Mutter vor, er möge noch ein bisschen bei Oma Leni spielen; sie will, dass wir für die Aufnahme Christian Ruhe haben.

169 *MUT: wollt(e)st (d)e [: du] der Frau+Rigol eigentlich auch erzählen, was mir [: wir] für (de)n Papa für Kuchen gebacken haben.

170 \%exp: ist zurück im Zimmer

171 *MUT: weisst (d)e [: du] das noch?

172 *RIG: ach@, o, der Papa hatte Geburtstag, ge(11)@o?

173 *MUT: ja@o.

174 *RIG: hm@o.

175 *MUT: was haben wir (de)nn gebacken am Sonntag Morgen?

176 *CHI: viele Art(en) Kuchen.

$177 \quad *$ CHI: wir ha(ben $)+\ldots$

178 *MUT: $+<$ viele Sorten, ja@o.

179 *CHI: Sonntag Moije@d [: Morgen] ham [: haben] wir (s)panischen

Apfelkuchen.

180 \%xspr: \$PHO

181 *CHI: un(d)den ha(ben) mer [: wir] mit Abfall gebacken.

182 *MUT: mit \&Apf [//] Aepfeln, ja@,o.

183 *MUT: spanischer Apfelkuchen.

$184 *$ RIG: hm@o.

$185 \quad *$ CHI: un(d) mit Abfall.

186 *MUT: ach@o Quatsch, doch net [: nicht] mit Abfall.

187 *MUT: hier@o, mach e(in)ma(l) das Puzzle fertig da.

188 *MUT: dass die Teile net [: nicht] verloren gehen.

189 *MUT: un(d) dann?

190 *MUT: was hat (de)nn der Papa alles geschenkt kriegt?

191 *MUT: was hatten wir dem denn geschenkt?

192 *MUT: weisst (d)e [: du] das noch?

193 *CHI: heiss [: weiss] ich nicht.

В эпизоде фиксируется стратегия взрослого к стимулированию воспоминания ребенка об отдельном эпизоде прошедшего дня рождения отца, которому испекли и подарили яблочный пирог $(\mathbf{1 7 1 - 1 7 2 , ~ 1 7 5 - 1 7 6 ) , ~ с ~}$ рефокусированием темы (175), способствующему поддержанию интереса и продолжению беседы, с репликами похвалы и одобрения (177, 182-183) правильного описания события ребенком $(176,177,179,181)$.

Первоначальные верно избранные стратагемно-тактические действия матери по «оживлению» воспоминаний о прошлых ситуациях, в которых принимал участие ребенок, с определенными эмоциональными поддержками, способствуют формированию автобиографических воспоминаний дошкольника, находящих свое выражение в отдельных отрывистых репликах последнего преимущественно на ранних онтогенетических ступенях развития. Интуитивно применяя метод прайминга и метод ассоциаций для создания ассоциативных семантических цепей, способных активизировать процесс воспоминания и 
повлечь за собой восстановление последовательности событий прошлого, взрослые конструируют схему автобиографического рассказа и затем уже автобиографической памяти.

Интересны, на наш взгляд, реплики матери и ребенка $(179,181,182$, $185,186)$ с элементами коррекции лексических единиц Apfel - Abfall, которые, во-первых, наглядно демонстрируют неполное усвоение словарного состава языка дошкольником данного возрастного интервала (при озвучивании в немецком языке приведенные слова являются неполными омофонами, при быстром произнесении в беглой речи они могут совпадать в звучании и ребенок вместо Apfel произносит Abfall, однозначно не зная значения этой лексической единицы), во-вторых, вносят неверную референцию, в результате чего воспоминание-фрагмент прошлой ситуации начинает обрастать неверными деталями, но не для ребенка, который еще не понимает этого, а для родителей, пытающихся исправить высказывание и, таким образом, весь фрагмент воспоминания в целом. Данный эпизод подтверждает наше положение о формировании АП совместно с когнитивно-речевым развитием дошкольника.

Эпизод 2.

CHI 3;04.07; MUT- мать; RIG - родственница семьи

16@Location: Wohnzimmer in der elterlichen Wohnung

17 @ituation: Die Kinder werden getauscht. Christian wird von der Tante übernommen, Sebastian kehrt in (da)s Wohnzimmer zurück. Er spricht heute viel, erzählt. Wir geraten in ein ausführliches Gespräch und er berichtet eine ganze Menge herrlichen Unsinns. Mutter ist etwas besorgt, weil er so albern, wie sie es bezeichnet, sei. Ich versuchen sie zu beruhigen. Wir sprechen über seine Gartenbeete und das Gemüse, das auf seinen drei Beeten wächst. Dann berichtet er von den Hasen und von Theo, der gerade auf Urlaub sei. Ich staune. (Theo war mit dem Heranwachsen immer bösartiger geworden, wurde in eine Herde gegeben und schließlich geschlachtet, was Sebastian noch nicht weiß). CHI berichtet von Unternehmungen mit dem Vater. Dann werden Vaters Fotos aus der Bundeswehrzeit hervorgeholt und CHI betrachtet sie genau. überall sucht er seinen Vater auf den Bildern, manchmal irrt er sich auch. Er erzählt viel Nonsens, neckt seine Mutter und mich.

154 *MUT: erzähl doch mal der Frau+Rigol, was ihr Mann gestern gemacht

hat.

155 *MUT: die hat das, glaub ich, noch gar nich(t) gesehen.

156 *MUT: die is $(\mathrm{t})$ nach Haus gekommen, da war es dunkel.

157 *MUT: und da hat die das noch gar ni(ch)t gesehen, was der Herr+Rigol gestern früh gemacht hat.

158 *CHI: die \&al [///] bei euch die verblühte Blume abdemäht [: abgemäht].

159 \%xspr: \$PHO

160 *RIG: hat er das gemacht?

$161 \quad * \mathrm{CHI}$ : hat er.

162 *RIG: und dann $<$ hat er $>$ [x 2] das abgeschnitten, was rausgewachsen is $(\mathrm{t})$ aus dem Garten,ge(11)@o?

163 *RIG: hat er das abgeschnitten jetzt?

164 *CHI: hat (e)s abdemäht [: abgemäht].

Реплики матери (155-157) стимулируют ребенка к рассказувоспоминанию об отдельном эпизоде прошедшего дня, когда они вместе с СНI были в гостях у RIG, муж которой днем убирал в саду отцветающие цветы, RIG этого не видела, поскольку пришла вечером. При этом реплика «die hat das, glaub ich, noch gar nich(t) gesehen» повторяется матерью, возможно, интуитивно, создавая эффект своеобразного прайминга, иными словами, ситуации с

XLinguae Journal, Volume 9 Issue 2, April 2016, ISSN 1337-8384 
эффектом напряжения, которое может выступить толчком к эпизодическому воспоминанию ребенка. Это ей удается: ребенок, не обладая еще умением связанного рассказа, одной репликой (158) объясняет то, что он видел в саду. Последующие реплики RIG выполняют не только функцию повторения и закрепления в памяти эпизода прошлого, но и скрепляют последовательность действий в саду $\mathbf{1 6 2} *$ RIG: und dann $<$ hat er $>$ [x 2] das abgeschnitten, was rausgewachsen is(t) aus dem Garten, ge(11)@o?), конструируя схему рассказа в определенной последовательности и вербализуя воспоминания ребенка. Детерминированность содержания воспоминания структурой рассказа необходима. При вербализации эпизода прошлого он должен вкладывается в схему рассказа: кто, что сделал, где, когда, зачем, почему, контекст. Если распределение воспоминания по этим ячейкам первоначально произойдёт неверно, то воспоминание останется ложным.

Нетрудно заметить, что практически все эпизоды начинаются с просьбы матери рассказать о том, что было вчера, что вчера и сегодня видел ребенок и какой совместной с взрослым деятельностью занимался: MUT: wollt(e)st (d)e [: du] der Frau+Rigol eigentlich auch erzählen, was mir [: wir] für (de)n Papa für Kuchen gebacken haben; MUT: $+<$ kannst doch ma(l) der Frau+Rigol erzählen, was ihr gestern und heut(e) im Kindergarten gemacht habt; MUT:kannst du ma(l) erzählen, was ich dir für einen geschenkt hab; MUT: hast der Frau+Rigol erzählt, was sich de(r) Papa da geleistet hatte? и т.д. При этом она многократно меняет и сужает ракурс воспоминания, фокусируя внимание дошкольника на главном; таким образом, маркер что/was приобретает контуры центра эпизода прошлого.

$\mathrm{C}$ нашей точки зрения такая тактика матери по своей прагматической направленности не является имплицитно «принудительной» (по Nelson, см. выше), но приглашает ребенка к совместной когнитивной деятельности: воспроизведению отдельного эпизода вчерашнего дня. Следующее считаем важным: воспроизводится всегда один эпизод из недавнего прошлого, которое маркируется лексически gestern и расположенным рядом хроно-маркером heut(e); таким образом, эксплицитно обозначается структура будущего воспоминания-рассказа: что/was, кто/ihr, когда=вчера и сегодня=, где сделал/gestern und heut(e) im Kindergarten gemacht habt. Компоненты «зачем, почему, контекст» на данной ступени онтогенеза не озвучиваются, поскольку относятся к причинно-следственным репрезентациям и формируются позднее.

Здесь также считаем важным подчеркнуть следующее: схема рассказавоспоминания, иными словами последовательность - кто, что сделал, где, когда, зачем, почему, контекст, - может нарушаться в зависимости от грамматикосинтаксических норм того или иного языка. Например, в речи немецкоговорящей матери из наших эпизодов превалирует следующее субъектно-предикатно-актантное расположение элементов высказывания, семантически маркирующих полевую структуру воспоминания: MUT: $+<$ kannst doch ma(l) der Frau+Rigol erzählen, was ihr gestern und heut(e) im Kindergarten gemacht habt - что, кто, когда, где сделал. На наш взгляд, такая последовательность не нарушает воспоминания, поскольку фиксирует или создает в сознании дошкольника определенную глубинную семантическую сеть, которая, усвоившись, и будет являться каркасом любого воспоминания, истинного, а не ложного.

Эпизод 3.

CHI 4;01.27; MUT- мать; RIG - родственница семьи.

18 @Location: Garten und Hof der Großeltern. 
19@Situation: CHI reißt zunächst Moos von der Mauer und erzählt dabei von Besuchen und seinen Hasen, dann zeigt er RIG die vielen Schneeglöckchen im Garten der Großeltern. Er pflückt einige Blumen und schmückt damit das Grab von Sandrabella, der Erdkröte; dabei äußert er sich über den Schmuck auf Gräbern. Danach zeigt er das Windrad und die Holzvorräte des Großvaters und das Beet, das er im kommenden Jahr beansprucht. Auf Anraten von OMA beginnt er mit der Einsaat von Radieschen und gießt den Wintersalat. Leider ist ein großer Teil der Aufnahme durch Windgeräusche erheblich gestört, so daß man manchmal nichts verstehen kann.

67 *MUT: kannst du ma(l) erzählen, was ich dir für einen geschenkt hab.

68 *CHI: Rollmops.

69 *RIG: Rollmops?

$70 \quad *$ CHI: $\quad$ das is(t) so (ei)n klein Has(e).

71 \%exp: RIG lacht.

72 *RIG: der heisst Rollmops?

$73 *$ MUT: hm@o.

$74 \quad *$ CHI: $\quad t<$ ja , weil der so dick is $(\mathrm{t})$ wie (ei)n Rollmops.

75 \%xspr: \$NS

$76 \quad$ *RIG: $\quad+<$ ach_so@o, kugelrund.

$77 \quad$ *MUT: hm@o.

$78 \quad *$ CHI: $\quad+<$ der $+\ldots$

79 *MUT: hm@o.

$80 \quad *$ RIG: hm@o.

81 *MUT: das war nämlich nur ein Baby, gell@o?

233 *MUT: kannst ja ma(l) Frau+Rigol erzählen, dass wir gestern Besuch

hatten.

234 *MUT: wer all(es) da war.

235 *RIG: was?

236 *CHI: $\quad+<$ die Ina, die Cosima.

$237 \quad$ *RIG: is(t) das wahr?

$238 *$ CHI: ja un(d) die Schwester noch von de(r) Ina.

239 *RIG: un(d) die Lotti?

240 *CHI: ja, auch da.

Наводящие вопросы матери (72), которые помогают создавать определенную последовательность рассказа-воспоминания, способствуют развитию причинно-следственных связей в повествовании и логическому мышлению дошкольника (74 *CHI: $\quad+<$ ja, weil der so dick is(t) wie (ei)n Rollmops): кролика-зайца, подаренного вчера ребенку, зовут Rollmops, потому что он выглядит как роль-мопс - маринованная сельдь. Примечательно, что в данном возрасте (CHI 4;01.27) у дошкольника сформированы причинноследственные связи и соответствия и, таким образом, схема - структура рассказа воспоминания расширилась за счет прирастания нового важного элемента «кто, что, кому, /где, когда/ сделал, ...+ почему», что не наблюдалось на более раннем онтогенетическом этапе.

Здесь, на наш взгляд, необходимо напомнить о проблеме фокуса и оформления детских высказываний, которые оказываются связанными друг с другом. Для детей раннего возраста характерны следующие проявления внешней речи: грубая вербализация; цельность как чувственный феномен; темарематическое структурирование цельности с опорой на просодически выделенные компоненты (фокусы); минимальная вербальная проработка высказывания с грубыми показателями элементов связанности; эллипсис 
ядерных конструкций во внешней речи; тенденция к выбору гиперонимического наименования.

Для правого полушария (о роли которого в онтогенезе мы писали выше: положение 1. данного исследования) важен референт, а не внутриязыковые отношения, отсюда идентификация «по имени», например, в случаях идентификации фраз с картинками, анализ пассивных и инвертированных конструкций исключен. Последовательность «имя-действиеимя» = «Ag-Pred-Pat» (предложенная схема является схемой глубинного синтаксирования) характерна именно для ранних этапов онтогенеза и также осуществляется правым полушарием. Данные нейролингвистов (Л.Я. Балонов, А.Р. Лурия и др.) обнаруживают правополушарность доязыковых уровней, где задействованы мотив и «смыслы», и на которых происходит глобальное выделение темы и ремы, а также восприятие всех просодических компонентов речи; а если учесть, что правое полушарие начинает функционировать с момента рождения ребенка (левое «включается» позднее), тогда вполне объяснима «рематичность» детских высказываний стадии раннего онтогенеза, но в узком смысле обсуждаемой проблемы. Известно, что когнитивное развитие опережает речевое, и это находит свое отражение на этапе «голофразиса», когда одним языковым знаком или жестом ребенок обозначает целую ситуацию. В данном случае, на наш взгляд, более приемлемо говорить о фокусных проявлениях, способных аккумулировать мотивы, интенции и тенденцию развертывания семантики высказывания дошкольника. Именно рематичностью и могут объясняться реплики-реакции ребенка $(236,238,240)$ обсуждаемого эпизода 3.

Эпизод интересен и тем, что в процессе длительной совместной и самостоятельной деятельности «СНI reißt zunächst Moos von der Mauer und erzählt dabei von Besuchen und seinen Hasen, dann zeigt er RIG die vielen Schneeglöckchen im Garten der Großeltern. Er pflückt einige Blumen und schmückt damit das Grab von Sandrabella, der Erdkröte; dabei äußert er sich über den Schmuck auf Gräbern. Danach zeigt er das Windrad und die Holzvorräte des Großvaters und das Beet, das er im kommenden Jahr beansprucht. Auf Anraten von OMA beginnt er mit der Einsaat von Radieschen und gießt den Wintersalat. Leider ist ein großer Teil der Aufnahme durch Windgeräusche erheblich gestört, so daß man manchmal nichts verstehen kann» взрослый время от времени пытается пробудить детские воспоминания о вчерашних (почеркиваем: всегда недавних) событиях, применяя чаще всего прием-стимул к рассказу (233 *MUT: kannst ja ma(l) Frau+Rigol erzählen, dass wir gestern Besuch hatten)._Примечательно, что взрослый практически озвучивает то, что должен вспомнить ребенок. Здесь наблюдается попытка эксплицитного конструирования несколько иной структуры рассказа-воспоминания: констатация вчера свершенного факта с последующей ассоциативной репликой-уточнением (234 *MUT: wer

all(es) da war). Прагматически ребенку остается либо опровергнуть, если это неверная номинация факта, либо вспомнить-подтвердить ключевые моменты вчерашнего визита гостей, что он и делает в последующих репликах-реакциях (236, 238, 240).

\section{Эпизод 4.}

CHI 4;09.27; MUT- мать; RIG - родственница семьи.

$16 @$ Location: Kinderzimmer CHI.

$17 @$ Situation: CHI erzählt von Kleintierausstellung, dann kommt er auf Briefe zurück, die er gerade anfertigt. Er faltet die Umschläge, MUT klebt sie mit Tesafilm zusammen. Dann diktiert $\mathrm{CHI}$ an irgendwelche Personen kleine Mitteilungen, die verpackt und überreicht werden. Meistens fordert er dann den 
Umschlag zurück. Er sortiert die Umschläge nach großen und kleinen in zwei verschiedene Schuhkartons. MUT versucht, ihm allerlei zu entlocken, er geht nur zum Teil darauf ein, beginnt aber wieder mit Neckereien, die MUT nicht sehr schätzt. Er spricht von der Laserkanone, die Forz (Flatus) heißt; offensichtlich hat er das von Kindern im Kindergarten übernommen. Von der beabsichtigten Reise in die Gießener Spielzeuggeschäfte mit Oma+Leni berichtet er nur wenig, trotz mehrerer Hinweise von MUT.

286 *MUT: hast der Frau+Rigol erzählt, was sich de(r) Papa da geleistet hatte?

287 *MUT: kannst ja ma(l) erzählen.

288 *CHI: de Pferdebahn fährt $[\% \mathrm{MA}] \mathrm{xxx}+\ldots$

289 *RIG: was is(t) da?

290 *RIG: ich $\mathrm{xxx}+/$.

$291 \quad *$ CHI: $\quad+<$ in dem Pack, da waren vier Rochees [\% Pralinen] drin + ..

292 *CHI: +, und für jeden eins, un(d) de(r) Papa hat die ganz Packun(g)

defuttert [: gefuttert].

293 \%xspr: \$SK

294 *RIG: hat die ganz(e) Packung gefuttert?

295 *MUT: vier Stück waren drin.

296 *MUT: für jeden ein(e)s.

297 *MUT: und dann hat de(r) Papa sie alle gefuttert, die Rochee.

298 *MUT: und zur Strafe ha(ben) mer [: wir] da (ei)ne grosse Kiste gekauft.

299 *MUT: und ham [: haben] s(i)e hier oben in deiner Schublade gelagert.

300 *MUT: und ich hab einen (ge)kriegt.

$301 *$ MUT: und jetz(t) sind s(i)e alle.

$302 \quad *$ RIG: aha@o.

303 *MUT: aber immerhin, den einen hab ich gekriegt, der mir zustand.

$304 \quad$ *RIG: sag ma(l), dann < musst du ma(l) selbst> [//], äh@o, musst du ma(l) Bonbons und Pralinen für den Papa kochen.

305 *CHI: Bonbons + .

Известно, что вопросы по своим иллокутивным установкам могут не только выражать запрос об информации, но и побуждать к совершению определенного вида деятельности: коммуникативной или физической. В реплике матери (286 *MUT: hast der Frau+Rigol erzählt, was sich de(r) Papa da geleistet hatte?) как раз и сосредоточен вопрос-побуждение к воспоминанию с экспликацией ключевых фигурантов ситуации недавнего прошлого, применяя интуитивно один из вариантов каркаса будущего автобиографического рассказа ребенка, который следующими, практически друг за другом, репликами фактически создал законченный рассказвоспоминание, что ранее не фиксировалось в нашем материале:

288 *CHI: de Pferdebahn fährt $[\% \mathrm{MA}] \mathrm{xxx}+\ldots$

291 *CHI: $\quad+<$ in dem Pack, da waren vier Rochees [\% Pralinen] drin + ..

292 *CHI: +, und für jeden eins, un(d) de(r) Papa hat die ganz Packun(g) defuttert [: gefuttert].

Таким образом, вероятнее всего, возраст 4-х лет является переломным этапом в формировании воспоминаний, именно как автобиографических, и обличения их в форму автобиографического рассказа.

\section{Эпизод 5.}

CHI 5;10.09; RIG - родственница семьи.

$16 @$ Location: Spielzimmer RIG.

$17 @$ Situation: CHI kommt und berichtet zunächst von der Kaninchenausstellung, an der er auch mit vier Tieren beteiligt ist. Er hofft auf den Hauptgewinn, einen Staubsauger, und äußert sich sehr altklug über seine Ansprüche

XLinguae Journal, Volume 9 Issue 2, April 2016, ISSN 1337-8384 
im Haus. Sie machen das Papageienspiel, CHI beteiligt sich mit Vergnügen. Danach will CHI mit dem Kaufladen spielen. RIG kauft ein und CHI bedient sie und versucht, wie immer, sie hereinzulegen. Sie unterhalten sich dabei über die Waren. Beim Bezahlen verlangt CHI einen Hunderter und einen Tausender. RIG schreit auf. CHI will sich auch mit einem Scheck begnügen, aber RIG erklärt ihm, dass das nichts nütze, da der Scheck nicht gedeckt sei, also kein Geld auf dem Konto. Das kann CHI nicht verstehen und will einen Scheck, begnügt sich dann aber mit einem Zweihundertmarkschein aus seiner eigenen Kasse. Wie immer will er sich vor dem Aufräumen drücken, aber RIG besteht auf seiner Beteiligung. Er sucht sich noch ein Video aus (Aristocats). Dann kommen Christian und der Großvater und CHI verabschiedet sich.

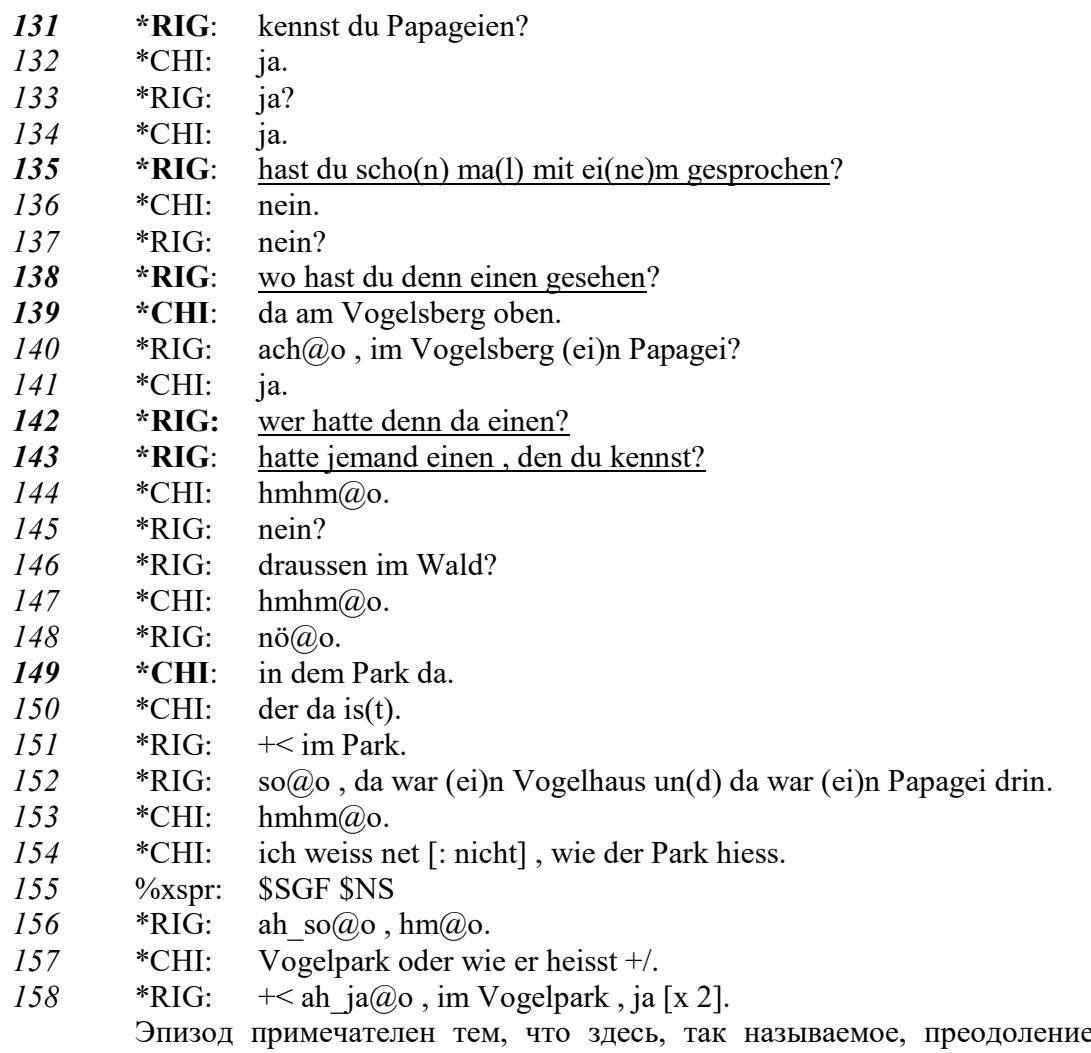
детской амнезии усилиями взрослого совершается в форме простого традиционного обмена репликами-мнениями, характерного для бытового дискурса. Простая, на первый взгляд, беседа в форме обмена мнений имплицитно содержит в себе каркас автобиографического рассказа:

Кто, что/кого (131)

Кто, когда, с кем /делал/(135)

Где, кто, кого /видел/ (138)

Кто, что\кого /имел к наличии/ (142)

Откладываясь в памяти ребенка, такая последовательность ключевых моментов способна генерировать любые воспоминания или служить средством для преодоления амнезии.

Эпизод 6. 
CHI 6;09.11; RIG - родственница семьи.

16 @Location: Spielzimmer RIG.

$17 @$ Situation: Langes, einleitendes Gespräch über die Krankheit der Zuchthasen, über die Betätigung bei Marvin und über die Schule. Dann SCHREIBEN: WöRTERBUCH. Er fügt vier Wörter hinzu. Wir beginnen mit FREIEM SCHREIBEN. Heute stecken wir mit Buchstaben. CHI steckt zunächst UMI, dann auf meine Bitte hin ESEL und KAMEL mit intensiver Analysearbeit. Dann HASE auswendig. CHI ist gründlich bei der Sache. In einem Zwischengespräch geht es um den Theaterbesuch am morgigen Tage, Kalif+Storch. CHI erzählt die Geschichte, soweit er sie vorgelesen bekommen hat. Wir beginnen mit LESEN: MEIN DEIN SEIN KEIN BALL. Er nennt die Wörter nach den Zeichnungen, liest aber nicht. Noch kann er nicht synthetisieren, aber das beunruhigt ihn, und er versucht Unsinn anzubieten. Wir bleiben nur kurz beim Lesen, weil er das wirklich noch nicht kann. Nun begibt er sich an den COMPUTER. Er entscheidet sich für SAMMY und wählt zunächst die Wetterstation, dann Film und schließlich die Werkstatt. Wieder druckt er aus, dieses Mal aus der Schwierigkeitsstufe zwei. Ich schlage ihm vor, die Biene zu rufen, damit er die Geräte mal in Aktion sieht. Das tut er, und wir haben viel Spaß damit. Abschied nach über einer Stunde.

394 *RIG: jetz(t) warst de [: du] bei (de)m Marvin zu Besuch, ja?

395 *RIG: habt ihr denn da was Schönes unternommen gemeinsam?

396 *CHI: $\quad+<j a$, erst war(en) mer [: wir] draussen un(d) ham [: haben],

äh@o, gearbeitet.

$397 \quad *$ CHI: die kleine(n) Steinche(n) aus de(m) Stall.

398 *CHI: der Opa macht doch de(n) Garte(n)pfad neu.

399 *RIG: ah_so@o, xxx.

$400 \quad$ *CHI: $\quad+\overline{<}$ un(d) da ha(ben) mer [: wir] die kleinen Steinche(n)

rausgelese(n) aus de(m) gro(sse), wo die grosse(n) Steine noch dabei waren.

$401 \quad \% x s p r: \quad$ SSGF \$NS

$402 \quad$ *RIG: $\quad+<$ da seid ihr ja mordstüchtig.

$403 \quad$ *CHI: dann ha(ben) mer [: wir] mein(en) Rasenmäherhefte vom Obi

angeguckt.

$404 \quad *$ CHI: eigentlich wollt(e) ich heut(e) zwei mitbringen, zwei andere vom

Wolfgang.

$405 *$ CHI: $\quad$ nur ich hab(e) (e)s net [: nicht] geschafft.

$406 \quad *$ RIG: ah@o, ja [x 2].

$407 \quad *$ RIG: hm@o [x 2].

$408 \quad$ *RIG: du hast (e)s nicht geschafft.

$409 \quad *$ CHI: muss ich ma(l) sehen, dass ich s(i)e wann an(d)ers mitbringe.

$410 \quad \% x s p r:$ \$SGF \$NS

411 *RIG: $\quad+<$ so , da habt ihr also $+\ldots$

412 *RIG: du kannst gern(e) von den Plätzchen essen, wenn du das willst.

$413 \quad *$ CHI: $\quad+<$ ja [x 2], nachher vielleicht.

$414 \quad *$ RIG: ja.

415 *RIG: also da habt ihr also wirklich so viele Sachen, äh@o, da geholfen und gemacht.

416 *RIG: das machst du gern(e), ge(11)@o, solche Arbeiten?

$417 \quad * \mathrm{CHI}:$ ja [x 2].

$418 \quad *$ RIG: hm@o.

419 *RIG: un(d) der Marvin macht das, glaub(e) ich, auch ganz ger(n),

ge(11)@o?

$420 * \mathrm{CHI}: \quad+<$ ja.

$421 \quad$ *RIG: ja.

XLinguae Journal, Volume 9 Issue 2, April 2016, ISSN 1337-8384 
$422 \quad$ *RIG: na@o, da wird der Grossvater sich ja sehr gefreut ham [: haben] über so (ei)ne tüchtige Hilfe.

Фактически, перед нами предстает свободное и последовательное изложение ребенком событий прошлого, оформленное различными синтаксическими конструкциями, включающими интродуктивные и постпозитивные актуализаторы. Начальные реплики взрослого $(394,395)$, как обычно, являются стимулом к оживлению воспоминаний и содержат направление - ключевые позиции развития подобных детских автобиографических рассказов. В возрасте 6-7 лет, как показывает наш материал, ребенок в состоянии самостоятельно развивать и актуализировать ключевые линии своего АР.

$396 \quad$ *CHI: $\quad+<j a$, erstwar(en) mer [: wir] draussen un(d) ham [:

haben],äh@o,gearbeitet.

397 *CHI: die kleine(n) Steinche(n) aus de(m) Stall.

398 *CHI: der Opa macht doch de(n) Garte(n)pfad neu.

$400 \quad$ *CHI: $\quad+<$ un(d) da ha(ben) mer [: wir] die kleinen Steinche(n)

rausgelese(n) aus de(m) gro(sse), wo die grosse(n) Steine noch dabei waren.

403 *CHI: dann ha(ben) mer [: wir] mein(en) Rasenmäherhefte

vom Obi angeguckt.

$404 \quad * \mathbf{C H I}: \quad$ eigentlich wollt(e) ich heut(e) zwei mitbringen, zwei

andere vom Wolfgang.

$405 \quad *$ CHI: nur ich hab(e) (e)s net [: nicht] geschafft.

Возрастной интервал от 9 лет и далее характеризуется расширением субъектно-предикатной сетки высказываний для выражения причинноследственных и хроно-пространственных отношений в трансляции событий прошлого и, как следствие, развитием и совершенствованием нарративных компетенций подростка.

II.

1. В дискурсивных практиках манифестируются разные организационные формы автобиографического материала и уровневая структура АП, семантическая обработка индивидуального прошлого определяет его дискурсивную реактуализацию. Анализ дискурсивных манифестаций сформированной АП подтверждает тезисы психологов о разнородных формах организации автобиографического материала в АП, конституируемого такими «яркими», «важными», «переломными», сущностными событиями» (Nurkova, 2008). Количественные подсчеты свидетельствует о превалирующей манифестации в исследуемых текстах реактуализируемых ярких, единичных событий $(65,12 \%)$, значительно меньшей вербализации воспоминаний о важных (13,95\%), сущностных (16,28\%), переломных событиях (4,65\%). Рассмотрим примеры объективации в рассматриваемых контекстах организационных форм автобиографического материала.

Приведем отдельные примеры.

Сущностное событие. В представленном ниже контексте бывший учитель (71 год) вспоминает о том, как он работал над календарем, посвященном истории Гамбурга. Реактуализируемое событие отражает суть личности, интересы рассказчика, а именно его любовь к родному краю, его истории, страноведению, а также увлечение писательской, просветительской деятельностью. Ja, der Kalender, der läuft jetzt schon acht Jahre, und ich habe da ein besonderes System; ich mache ein Drittel von Hamburg, wie es heute neuerstanden ist, ein Drittel von dem, was vom alten Hamburg noch da ist und das letzte Drittel, das sind Bilder aus Museen oder aus der Staatsbibliothek, die Hamburg 
vor hundert oder zweihundert Jahren zeigen. Und grade diese alten Stiche oder sonst Zeichnungen vom alten Hamburg, die gefallen außerordentlich. Nur der Verleger sagt, nicht so viel alte, denn es gehen viele Kalender ins Ausland, und die da draußen sind, die wollen gerne mal sehen, wie es heute in Hamburg aussieht. Ja, ich habe sowohl Daten aus der Geschichte Hamburgs da unten drunter, ich habe aber daneben, oder, wenn es dort keinen Platz hatte, denn auch darunter eine Beschreibung des Zustandes, das Bild zeigt, also historische Hinweise, wie es entstanden ist, wozu es gedient hat, oder was sonst Interessantes von diesem Bild zu berichten ist. Ja, die Bürgervereine, die sind oft gekommen und sagen: Können Sie nicht mal über alte Hamburger Verhältnisse, also sagen wir mal, wie's plattdeutsch heißt: «Uut Vadders Tieden», können Sie daraus nicht einmal sprechen zu uns? Dann habe ich mir Bilder machen lassen zum An-die-Wand-werfen. Und so sind eine Reihe von Vorträgen entstanden, die ich, na, ich kann sagen, in sämtlichen Hamburger Bürgervereinen gehalten habe, und wo die Leute auch besonders dann sehr zufrieden waren, wenn ich diese Vorträge auf Plattdeutsch gehalten habe (DSAv; Interaktion PF018). - Да, календарь издается уже 8 лет, и у меня особая система. Одна треть посвящена сегодняшнему, новому Гамбургу, одна треть - тому, что осталось от старого Гамбурга, последняя треть - картины из музеев и государственных библиотек, на которых можно увидеть город, каким он был 100 или 200 лет назад. И как раз эти старые гравюры или рисунки старого Гамбурга больше всего нравятся. Издатель говорит, что не нужно давать так много старого материала, потому что календари идут заграницу, а там хотят видеть современный город. У меня есть и исторические данные, внизу или рядом, если мало места (потому что необходимы подписи к картинкам о том, что изображено), которые информируют об истории возникновения, цели, функциях и других интересных фактах. Да, ко мне часто приходили представители гражданских объединений и говорили: «Вы бы не могли нам рассказать о старом Гамбурге, о той жизни, так сказать, как наши отцы это видели и знали?». Я делал диа-материалы для наглядности. Так возник цикл докладов, которые я прочитал практически во всех гражданских объединениях Гамбурга, и во время которых люди особенно довольны были, когда я говорил на диалекте «Платт», которым здесь раньше все пользовались. Вспоминающий субъект старательно, с любовью к деталям работал над календарем и реализовал в нем свою собственную систему представления материала. Респондент доволен и горд своей работой, собой, увлечен творчеством, описывает мотивы, цели, впечатления других людей, участников описываемых ситуаций, а именно издателя и слушателей его выступлений. Объект реактуализации оценивается говорящим позитивно, на что указывает употребляемые в повествовании ЛЕ с положительной семантикой (außerordentlich gefallen, gerne, sehr zufrieden, Interessantes). Реализуемые тональности повествования - рефлектирующая, воодушевленная и самодовольная.

Переломное событие. В приводимом ниже контексте биографического интервью респондент (21-летняя студентка) вспоминает о своих школьных годах, когда произошло переломное событие в ее жизни (переезд с семьей в Рейнскую область), повлиявшее, в том числе, и на ее характер. In den ersten sechs Jahren war es sehr schwierig für mich, dadurch, dass die Rheinländer eine ganz andere Mentalität haben und ich eigentlich mehr die westfälische Art von meiner Mutter geerbt habe, wurde ich nicht richtig warm. Ich war immer als sehr schüchtern bekannt. Aber ich sagte mir dann, als ich sechs Jahre nun auf der Schule war, dass sich das ändern müsse, bin etwas mehr aus mir heraus gegangen, und man meint heute, dass ich doch mehr ein rheinischer Typ sei. Ich war hinterher Klassensprecherin und, wie man so sagt, spielte so etwas die erste Geige. Ja, und

XLinguae Journal, Volume 9 Issue 2, April 2016, ISSN 1337-8384 
muss sagen, dass ich mich in den letzten drei Jahren sehr gut mit meinen Mitschülerinnen verstanden habe (DSAv; Interaktion PF035). Молодая девушка рассказывает, что она должна была приспособиться к новым условиям, «вжиться», привыкнуть и сойтись с новыми людьми. Жители Рейнской области более открытые, общительные, и после переезда ей говорили, что у нее не достаточно душевного тепла, что она сильно отличается от местных жителей своей замкнутостью и робостью. После 6 лет в школе рассказчица решает, что должна поменять свое отношение к окружающим, изменить себя. Она стала активно участвовать в жизни школы, больше общалась и нашла взаимопонимание с одноклассниками, и сегодня все уверены, что она коренная жительница. Субъект воспоминания описывает свои размышления, мотивы действий, цели, ощущения. Рассказчица довольна собой и оценивает изменения как позитивные и свои действия как успешные. В описании представлена характеристика «героини» до и после ее адаптации сравниваются два самоописания. Тональность повествования - рефлектирующая с элементами самодовольной тональности.

Превалирующими при манифестации реактуализации сущностных событий индивидуального прошлого являются рефлектирующая $(45,9 \%)$ и воодушевленная $(26,27 \%)$, далее следуют эмоциональная $(18,03 \%)$, самодовольная $(8,2 \%)$ и ностальгическая $(1,6 \%)$ тональности повествования. Языковая манифестация реактуализации переломных событий индивидуального прошлого коррелирует с превалирующей реализацией рефлектирующей тональности (50 \%), реже с эмоциональной $(22,22 \%)$, самодовольной $(16,67 \%)$, воодушевленной и критичной (по 5,55\%) тональностями. При манифестации в биографических интервью реактуализации важных событий индивидуального прошлого в биографических интервью наиболее релевантной является рефлектирующая тональность $(60,85 \%)$, далее следуют воодушевленная $(13,04 \%)$, эмоциональная $(8,7 \%)$, ностальгическая $(6,52 \%)$, самодовольная $(6,52 \%)$ и критичная $(4,35 \%)$ тональности повествования. При реактуализации единичного, яркого события наиболее часто реализуется рефлектирующая $(28,23 \%)$ и воодушевленная $(26,61 \%)$, реже эмоциональная $(16,13 \%)$, ностальгическая $(14,52 \%)$, ироничная $(8,06 \%)$, критичная $(4,84 \%)$ и самодовольная $(1,61 \%)$ тональности. Реактуализация в большинстве случаев направлена на позитивно оцениваемый объект. Наиболее релевантными при вербализации всех форм автобиографического материала в дискурсивных практиках являются рефлектирующая (42,37 \%), а также эмоциональная $(22,7$ \%) и воодушевленная (12,12\%) тональности, а критичная, ироничная, ностальгическая и самодовольная выступают в качестве дополнительных.

В автобиографических дискурсивных практиках манифестируются чаще всего яркие, единичные события индивидуального прошлого. Манифестация яркого события характеризуется динамичностью, эмоциональностью описания, воспроизведением временных и пространственных признаков ситуации. Повествование выстраивается как воссоздание целостной картины образа события, как эмоционально-смысловая интерпретация, часто ограниченная рамками прошлого. Манифестация реактуализации важных событий включает анализ их последствий и роли в жизни автора, соотнесение с некой жизненной темой, а также эмоциональное переживание отношения фрагмента прошлого к актуальной ситуации, сегодняшним мотивам и потребностям индивида. Описание выстраивается как ретроспекция из сегодняшнего дня. Временная перспектива детерминируется субъективной локализацией события на оси индивидуальной истории и может охватывать относительно большие тематически объединенные промежутки 
времени. Манифестация реактуализации сущностных событий как некого символа, обобщающей, конгруентной метафоры личности содержит вербализованные переживания идентичности, сопоставления характеристик события и лица. При реактуализации переломного события описание соответствующих воспоминаний представляется как субъективная оценка изменений и их последствий для актуальных мотивов и потребностей индивида, как рефлексия, соотносящая друг с другом два самоописания. Временная перспектива повествования при этом разбивается на два измерения («до» и «после») как континуальные интервалы самоидентичности личности.

Со степенью семантической обработки автобиографического материала и частично с его организационными формами сопряжена уровневая структура АП (Nurkova, 2008), что также находит отражение в соответствующих дискурсивных практиках. Дискурсивные практики подтверждают, что АП имеет уровневую структуру, включающую: конкретные эпизоды-случаи (воспроизведение в памяти определенной, единичной ситуации); воспоминания о судьбоносных событиях (обращение к важным или переломным событиям индивидуального прошлого); жизненные темы (отражают значимые на протяжении всей жизни сферы активности субъекта, указывают на преемственность этапов личной истории субъекта); целостное интегральное представление о своей судьбе.

2. В соответствии с культурно обусловленными жизненными сценариями реализуемые в автобиографических практиках тематические доминанты соотносятся с личностными смыслами.

Выявленные в исследуемом материале тематические доминанты (регулярные объекты реактуализации) могут быть соотнесены с тематическими группами, выделенными Г. Лефлером (Löfler, 1988: 108), наиболее релевантными из которых являются: 1) жизнь общины или союза $(36,55 \%) ; 2)$ праздничные поводы в биографии (рождение, свадьба, семейные события) $(26,36 \%)$; 3) события профессиональной жизни $(15,23 \%) ; 4)$ школа, образование $(10,15 \%) ; 5)$ болезнь, несчастный случай $(6,63 \%) ; 6)$ военные события, служба в армии, участие в войне, ранения, пленение, освобождение $(5,08 \%)$.

Выделенные нами в дискурсивных практиках тематические доминанты частично коррелируют также с выявленными А.Л. Ереминым (Eremin, 2005) стрессогенными факторами, влияющими на функционирование, экологию интеллектуальных систем, которые, по сути, представляют собой точки на линии индивидуальной жизни, характеристики которых обусловливают их присутствие и наиболее частую реактуализацию или осознанное активное вытеснение: каникулы, поездки $(19,02 \%)$; рождество, другие праздники $(17,7 \%)$; поступление, окончание школы $(7,08 \%)$; изменение ответственности на работе $(6,19 \%)$; смена места жительства $(5,31 \%)$; изменение профиля работы $(4,87 \%)$; изменения в социальной активности $(4,87 \%)$ смена места работы $(4,42 \%)$; собственная травма или болезнь (3,98\%); выдающиеся личные достижения $(3,54 \%)$; изменение условий и времени работы $(2,65 \%)$; изменение финансового статуса $(2,65 \%)$; женитьба, замужество $(2,21 \%)$; изменение жилищных условий $(2,21 \%)$; болезнь члена семьи $(1,77 \%)$; разлука супругов $(1,77 \%)$; смерть близкого члена семьи $(1,33 \%)$; появление нового члена семьи $(1,33 \%)$; смерть супруга $(2,243 \%)$; увольнение с работы $(0,88 \%)$; развод $(0,88 \%)$. Данные цифры указывают на то, как часто реактуализация соответствующих событий манифестируется в сформированном корпусе эпизодов, но не на их важность в индивидуальной истории жизни субъекта, поскольку самые значимые события в судьбе индивида носят единичный

XLinguae Journal, Volume 9 Issue 2, April 2016, ISSN 1337-8384 
характер (например, женитьба, развод, потеря близких людей и т. д.). Как показывают приведенные списки, тематические доминанты концентрируются вокруг личностных смыслов, детерминируемых мотивами, потребностями и ценностями субъекта.

3. Обращение к АП детерминируется мотивами личности, дискурсивные параметры реактуализации прошлого опыта определяются реализуемыми функциями АП.

Анализ языкового материала свидетельствует, что обращение к индивидуальному прошлому детерминируется разными целями (Василевская, 2008), в соответствии с чем можно говорить о дискурсивной манифестации разных функций АП, наиболее часто манифестируемыми из которых являются: прагматическая функция АП (апелляция к содержанию АП с целью решения конкретных задач в настоящем времени и планирования будущих действий; превалирует обращение к отрицательным воспоминаниям и реализации позиции субъекта-наблюдателя); саморегуляционная функция (реактуализация автобиографического материала с целью управления своим психическим состоянием, повторного переживания фрагментов прошлого; доминируют обращение к позитивным воспоминаниям и позиция субъекта-участника); коммуникативная функция (автобиографическое содержание используется для установления / развития контакта; практически одинаково частое воспроизведение позитивных и негативных воспоминаний и реализация позиций субъекта-наблюдателя и субъекта-актера; выбор позиции определяется представлениями говорящего о желаемом результате - разделение содержания или эмоций / идентичности субъекта). Реактуализация фрагмента прошлого с позиции субъекта-актера предполагает вербализацию деталей чувственного восприятия, описание душевного состояния, эмоциональных переживаний субъекта, а с позиций субъекта-наблюдателя - несколько дистанцированное, без наличия множества деталей, менее эмоциональное повествование. Наиболее релевантными тематическими доминантами в рамках прагматической функции АП являются «человек и его характеристики», «содержание разговора, письменного документа или их части», «место, интерьер, месторасположение», «негативные обстоятельства», «конкретные данные», «нейтральные события и их участники», «оценка своих поступков»; при манифестации саморегуляционной функции - «позитивные переживания», «негативные переживания», «смешанные переживания»; коммуникативной функции «события», «человек», «место, его характеристики».

\section{Заключение}

Изучение генезиса и развития форм АП в раннем онтогенезе показывает, что АП не является врожденной структурой. Реализуясь как автобиографический рассказ в ранних периодах онтогенетического развития дошкольника, АП проходит сложный этап своего становления, который сопряжен со становлением речи, формированием и усовершенствованием развития когнитивно-речевых способностей и дискурсивных компетенций субъекта. Детские воспоминания (преодоление детской амнезии), по мере эволюции когниций и речи дошкольника, генерализуются по схеме, которая претерпевает следующие вариации (характерно для немецкоговорящих партнеров по коммуникации): а) кто, что, когда, где сделал; б) что, кому, кто сделал; в) кто, что сделал, где, когда ...+ почему; г) кто, что, кому, /где, когда/ сделал, ...+ почему; д) кто, что, когда (сделал); е) кто, что сделал, где, когда, зачем, почему, ...+ контекст (поздние этапы филогенетического развития).

Анализ автобиографических практик взрослого человека свидетельствует об объективации в дискурсивных практиках функционально- 
структурных характеристик АП. Подсистема автобиографической памяти имеет интерактивный и интерсубъектный характер, дискурсивная манифестация ее функционирования отражает ценностную нагруженность ее объектов и сопряженность АП с эмоциональными переживаниями. В дискурсивных практиках манифестируются разные формы организации автобиографического материала, уровневая структура АП и, кроме того, мотивы, цели обращения к индивидуальному прошлому (прагматическая, саморегуляционная, коммуникативная функции АП), что в совокупности детерминирует дискурсивные параметры. Дискурсивные практики опосредуют формирование и функционирование АП, переорганизуя посредством фиксируемых языком понятий довербальное событие индивидуального прошлого. Автобиографическая память функционирует как личностно-когнитивная система, в рамках которой фрагменты индивидуального прошлого упорядочиваются и систематизируются как конкретные организационные формы, принадлежащие определенным уровням памяти, предполагающим разную семантическую обработку и степень схематизации. Реактуализация автобиографического материала способствует социализации и индивидуализации, разделению субъективного отражения индивидом его жизненного пути, формированию персональной и автобиографической идентичностей, регуляции идентичностей в структуре идентичности личности. Анализ тематических доминант и языковых средств их объективации, частотность вербализации воспоминаний о ярких событиях, конкретных эпизодах, позиции субъекта-актера и эмоциональной тональности повествования позволяют сделать вывод о реализации в немецкой лингвокультуре формулы реактуализации индивидуального прошлого «единичное - яркое - эгоцентричное».

\section{Bibliograpic references}

ALJUSCHEVA, A.R. 2012. Kulturnij shiznennij scenarij kak sredstvo formirovanija avtobiograficheskoj pamjati: diss. ... magistra psihologii. Moscow.

ALJUSCHEVA, A.R. 2012. Ovladenie repertuarom kulturnih shiznennih scenariev kak faktor razvitija makrostrukturi avtobiograficheskoj pamjati. Retrieved from: http://psystudy.ru/index.php/num/2012v5n25/732-alyusheva25.html. ISSN 2075-7999. BADDELEY, A.D. 1992. What is autobiographical memory? In Theoretical perspectives on autobiographical memory. Dordrecht: Kluwer, pp. 13-29. ISBN 97894-015-7967-4.

BLAGUTINA, V.V. 2009. Kak ustroena pamyat? Sistemy pamyati i ih vzaimodeystvie. In La Recherche, $\mathrm{n}$ 7-8. Retrieved from: http://www.inauka.ru/analysis/article96468/print.html. ISSN 0029-5671.

BOWDEN, E.M. - BEEMAN, M.J. 1998. Getting the right idea: Semantic activation in the right hemisphere may help solve insight problems. In Psychological Science, vol. 9, n 6, pp. 435-440. ISSN 0956-7976.

CHERNIGOVSKAJA, T.V. - DEGLIN, V.L. 1986. Brain functional asymmetry and neural organization of linguistic competence. In Brain and Language, vol. 29, pp. 141 153. ISSN: 0093-934X.

CHILDES - Child Language Data Exchange System. Transcript Browser. Retrieved from: http://childes.psy.cmu.edu/browser/index.php.

CONWAY, M.A. - RUBIN, D.C. 1993. The structure of autobiographical memory In Theories of memory. Hove, U.K.: Erlbaum, pp. 103-137. ISBN 0748625038.

CRAIK, F. - MOROZ, T. - MOSCOVITSCH, M. - STUSS, D. - WINOCUR, G TULVING, E. - KAPUR, S. 1999. In search of the self: a positron emission tomography study. In Psychological Science, vol. 10, pp. 26-34. ISSN 0956-7976. 
DECETY, J. - CHAMINADE, Th. 2003. When the self represents the other: A new cognitive neuroscience view on psychological identification. In Consciousness and Cognition, vol. 12, pp. 577-596. ISSN: 1053-8100.

DECETY, J. - SOMMERVILLE, J. 2003. Shared representations between self and other: a social cognition neuroscience view. In Trends in Cognitive Science, vol. 1, p. 527. ISSN 1364-6613.

DEVINSKY, O. 2000. Right cerebral hemisphere dominance for a sense of corporeal and emotional self. In Epilepsy and Behavior, vol. 1, pp. 60-73. ISSN1525-5050.

DOWNAR, J. - CRAWLEY, A.P. - MIKULIS, D.J. - DAVIS, K.D. 2002. A cortical network sensitive to stimulus salience in a neutral behavioral context across multiple sensory modalities. In Neurophysiol, vol. 87 (1), pp. 15-20. ISSN: 0022-3077.

DSAv - DEUTSCHES SPRACHARCHIV. Retrieved from: http://dsav-oeff.idsmannheim.de/DSAv.

EREMIN, A.L. 2005. Ekologiya i fiziologiya intellektualnyh system, zakonomernosti informacionnoi ekologii. In Noogenez i teoriya intellekta. Krasnodar: SovKub. 356 p. ISBN 5-7221-0671-2.

FIVUSH, R. - BAUER, P.J. 2010. The Emergence of Recollection: How we learn to recall ourselves in the past. In The act of remembering: Towards an understanding of how we recall the past. J.H. Mace (Ed.). Oxford, UK: Wiley-Blackwell. pp. 259-283. ISBN: 978-1-4051-8903-3.

GORELOV, I.N. 2003. Izbrannie trudi po psiholingvistike. Moscow: Labirint. 320 p. ISBN 5-87604-025-8.

KEENAN, J. P. - WHEESLER, M. - GALlUP, G. Jr. - PASCUAL-LEONE, A. 2000. Self-recognition and the right prefrontal cortex. In Trends in Cognitive Sciences, vol. 4, pp. 338-344. ISSN 1364-6613.

KEENAN, J.P. - NELSON, A. - O'CONNOR, M. - PASCUAL-LEONE, A. 2001. Self-recognition and the right hemisphere. In Nature, n. 409, p. 305. ISSN 0028-0836. LÖFLLER, H. 1988. Vergangenheit in mündlicher Überlieferung aus germanistischer Sicht. In Vergangenheit in mündlicher Überlieferung. Stuttgart: Teubner. pp. 100-113. LOU, H.C. - LUBER, B. - CRUPAIN, M. - KEENAN, J.P. - NOWAK, M. KJAER, T.W. - SACKEIM, H.A. - LISANBY, S.H. 2004. Parietal cortex and representation of the mental self. In Proc. Natl. Acad. Sci. U. S. A., vol. 101, pp. 6827-6832. ISSN 1091-6490.

LURIJA, A.R. 1998. Jazik i soznanije. Moscow. 336 p. ISBN: 5-211-03957-2.

MARKOWITSCH, H.J. 1995. Anatomical Basis of Memory Disorders. In The Cognitive Neuroscience. Gazzaniga, M.S. (Ed.). Cambridge. MA: MIT Press. pp. 665-679. ISSN 1758-8928.

NELSON, K. 1991. Remembering and telling: A developmental story. In Journal of Narrative and Life History, vol 1, n. 2-3, pp. 109-27. ISSN 1053-6981.

NELSON, K. 1993. Explaining the Emergence of Autobiographical Memory in Early Childhood In Collins, A.F. -Gathercole, S.E. -Conway, M.A. - Morris, P. E. (Hrsg.) Theories of Memory, Hove, UK: Erlbaum. pp. 355-385. ISBN 0748625038.

NELSON, K. - FIVUSH, R. 2004. The emergence of autobiographical memory: A social cultural developmental theory. In Psychological Review, n. 111(2), pp. 486-511. ISSN 0033-295X.

NEWEN, A. 2000. Selbst und Selbstbewusstsein aus philosophischer und kognitionswissenschaftlicher Perspektive. In Selbst und Gehirn. Paderborn: MentisVerlag. pp. 19-56. ISBN 9783897850538.

NEWEN, A. - MEIXNER, U. (Hrsg.). 2003. Seele, Denken, BewußtseIn Zur Geschichte der Philosophie des Geistes (von Platon bis Husserl). Verlag: de Gruyter. 412 p. ISBN 978-3110174052. 
NIKANOROVA, L.V. 1998. Genez avtobiograficheskogo rasskaza. In Psychology.ru. Retrieved from: http://www.psychology.ru/lomonosov/tesises/gf.htm. ISSN 21527199.

NOURKOVA, V.V. 1996. Avtobiograficheskaja pamjat kak problema psihologicheskogo issledovanija. In Psihologicheskij shurnal, v. 17, n. 2, pp. 16-29. ISSN 0205-9592.

NURKOVA, V.V. 2000. Sverschonnoje prodolshaetsja: Psihologija avtobiograficheskoi pamjati. Moscow. 316 p. ISBN 5-204-00207-3.

NURKOVA, V.V. 2004. Rol avtobiograficheskoi pamyati v structure identichnisti lichnosti. In Mir psihologii, n. 2 (38), pp. 77-86. ISSN 2073-8528.

NURKOVA, V.V. - MITINA, O.V. - JANCHENKO, E.V. 2005. Sguschenija v subjektivnoj kartine proschlogo. In Psihologicheskij shurnal, n. 26(2), pp. 22-32. ISSN 0205-9592.

NURKOVA, V.V. 2008. Analiz fenomenologii avtobiograficheskoi pamyati s pozicii kulturno-istiricheskogo podhoda. In Kulturno-istoricheskaya psihologiya, n. 1, pp. 17-26. ISSN 1816-5435.

NURKOVA, V.V. 2009. Kulturno-istoricheskij podhod k avtobiograficheskji pamjati: diss. ... d-ra psihol. nauk. MGU, Moscow. 661 p.

NURKOVA, V.V., ALJUSCHEVA, A.R. 2012. Shizn kak roman: opit chtenija i uroven razvitija avtobiograficheskji pamjati. In Chtenije i poznanije. Materiali 16-i nauchno-prakticheskoj konferencii po psihologii, filosofii i pedagogike chtenija. 4-5 aprelja. Moscow. pp. 61-64. ISBN 978-5-8429-1040-8.

PETROVA, A.A. 2010. Bazisnie pokazateli processa usvoenija jazika i rechi kak osnova modelirovanija v ontogeneze. . In Vestnik Cheljabinskogo gosudarstvennogo universiteta, n. 7b, pp. 321-329. ISSN 1994-2796.

PETROVA, A.A. 1997. Intonacija v rannev ontogeneze: tendencii usvoenija i vozmoshnosti viavlenija patologii rehi. In Vestnik Volgogradskogo gosudarstvennogo universiteta. Serija 2, Filologija, vol. 2, pp. 95-99. ISSN 1998-9911.

PETROVA, A.A. 2003. Kvazikommunikacija rebenka $\mathrm{v}$ rannem vozraste. In Vozrastnoje kommunikativnoje povedenije. Voronesh, vol. 1, pp. 17-30. ISBN 588242-208-6.

PLATEK, S. - KEENAN, J. - GALLUP, G.JR. - MOHAMED, F. 2004. Where am I? The neurological correlates of self and other. In Cognitive Brain Research, vol. 19, pp. 114-122. ISSN 0926-6410.

Referenzrahmen zur altersspezifischen Sprachaneignung / Hrsg.: K. Ehlich, U. Bredel, H. Reich. -Berlin : BMBF, 2008. Band n. 29/1, pp. 18-21. (a)

Referenzrahmen zur altersspezifischen Sprachaneignung - Forschungsgrundlagen / Hrsg.: Ehlich K., Bredel U., Reeich H. - BerlIn BMBF, 2008. Band n. 29/2, 350 p. (b) ROTENBERG, V.S. 1982. Funktionale Dichotomie der Gehirnhemispheres und die Bedeutung der Such-Aktivität für Physiologische und Psychopathologische Prozesse. In G. Ammon (ed.): Handbuch der Dynamische Psychiatrie. München: Ernst Reinhardt, vol. 2, pp. 275-335. ISBN 978-3497008643.

ROTENBERG, W. 2009.Mezhpolusharnaya asimmetriya, eyo funkcii i ontogenez. Moscow: Nauchnyi mir. Retrieved from: http://rjews.net/v_rotenberg/glava6.html. ISBN 5-09-001050-1.

ROTENBERG, V.S. - WEINBERG, I. 1999. Human memory, cerebral hemispheres, and limbic system. A new approach. In Genetic, Social and General Psychology Monographs, vol. 125(1), pp. 45-70. ISSN 8756-7547.

RUBIN, K.H. - BURGESS, K.B. - KENNEDY, A.E. - STEWART, S. 2003. Social withdrawal and inhibition in childhood. In E. Mash, R. Barkley (Eds.) Child psychopathology. New York: Guilford Press. pp. 372-406. ISBN-13: 9781572306097. 
SAUGSTAD, OD. 1998. Resuscitation with room-air or oxygen supplementation. In Clinics in Perinatology, vol. 25, pp. 741-756. ISSN: 00955108.

SCHORE, ALLAN N. 2003. The human unconscious: the development of the right brain and its role in early emotional life. In Emotional Developmental in Psychoanalysis, Attachment Theory, and Neuroscience: Creating Connections. pp. 2354. ISBN 978-1583911358.

SHAMMI, P. - STUSS, D. 1999. Humor Appreciation: A Role of the Right Frontal Lobe. In Brain, vol. 122 (4), pp. 657-66.

SCHÜTZE, F. 1984. Kognitive Figuren des autobiographischen Stegreiferzählens. In Biographie und soziale Wirklichkeit. Stuttgart. pp. 78-117. ISBN 978-3476005489.

SHAMAY-TSOORY, S.G. - TOMER, R., et al. 2003. Characterization of empathy deficits following prefrontal brain damage: The role of the right ventromedial prefrontal cortex. In Journal of Cognitive Neuroscience, vol. 15 (3), pp. 324-337. ISSN 0898-929X.

SHAMNE, N.L. - REBRINA, L.N. 2013.Category of memory: principles of linguistic description. In Journal of Siberian Federal University. Humanities \& Social Sciences, n. 6 (7), pp. 1085-1092. ISSN 1997-1370.

SPRINGER, S. - DEUTSCH, G. 1981. Left brain, right brain. San Francisco: W.H. Freeman, $142 \mathrm{p}$.

VASILEVSKAYA, K.N. 2008. Individualno-tipologicheskie osobennosti avtobiograficheskoi pamyati: avtoreferat diss.... kandidata psicholog. nauk. Moscow. $26 \mathrm{p}$.

VIGOTSKI, L.S. 1999. Mischlenie i rech. Psihologicheskije issledovanija. Moscow, Labirint. 419 p. ISBN 5-87604-097-5.

Words: 10612

Characters: 71500 (39, 7 standard pages)

assoc. prof. Anna Petrova Dr. hab.

assoc. prof. Larissa Rebrina Dr. hab.

Department of German Philology

Institute for philology and cross-cultural communication

Volgograd State University

Prospect Universitetsky, 100, Volgograd, 400062, Russia

petrova16@mail.ru

Reblora@mail.ru 